\title{
Utilizing Animal Characters of a Mobile Augmented Reality (AR) Reading Kit to Improve Preschoolers' Reading Skills, Motivation, and Self-Learning: An Initial Study
}

\author{
https://doi.org/10.3991/ijim.v15i24.26673
}

\author{
Hafizul Fahri Hanafi $\left.{ }^{\bowtie}\right)$, Kung-Teck Wong, Muhamad Hariz Muhamad Adnan, \\ Abu Zarrin Selamat, Nur Azlan Zainuddin, Mohd Faizal Nizam Lee Abdullah \\ Universiti Pendidikan Sultan Idris (UPSI), Tanjung Malim, Malaysia \\ hafizulafskik. upsi.edu.my
}

\begin{abstract}
This study developed and used a mobile Augmented Reality (AR) reading kit to help preschool students recognize alphabets and read simple words more effectively. This study was based on the quantitative approach involving an experimental methodology that used a one-group pretest-posttest design. In this study, the variables of interest to be measured were students' reading skills, motivation, and self-learning. The learning treatment involved a series of reading sessions using the novel learning application that spanned three weeks, with each session lasting for two hours. The sample of this study comprised 60 preschool students, whose ages ranged from four to six, who were selected from three different preschools. The effectiveness of the novel-reading kit was evaluated in terms of students' learning performance, learning motivation in reading, and self-learning. The data for the former were gathered from pre-testing and post-testing. At the same time, a survey was administered to the students to elicit their opinions and feedback on the last two factors. Furthermore, all descriptive and inferential statistical procedures have been selected to analyze the data. Specifically, a one-way analysis of variance (ANOVA) was applied to analyze the data, which demonstrated significant differences in the students' reading skills, motivation, and self-learning before and after the learning interventions. These findings showed the students could recognize alphabets more accurately, read simple words more intelligently, become more motivated to read and be highly engaged in self-learning using the mobile AR reading kit.
\end{abstract}

Keywords - mobile augmented reality, motivation, preschool students, reading skills, self-learning

\section{$1 \quad$ Introduction}

Undeniably, there is a growing need for online learning or virtual learning during the Covid-19 pandemic to sustain student learning through this difficult time [1][2]. All over the world, conventional physical 'face-to-face' learning has now been replaced by online or virtual learning to ensure the safety of children [3]. As such, teaching 
practitioners must rely on a broad spectrum of technologies to deliver learning content and impart knowledge to students transcending time and place [4]. Over the recent years, emerging mobile technologies using high-quality smartphone cameras and smart glasses, such as HoloLens, have been widely used to enable the integration of 3D information to transmit information and data users interactively [5].

Arguably, the interactions between students and digital learning objects help engender learning environments in which students become more engaging, active, allowing them to develop positive attitudes and motivation [6]. By contrast, traditional learning approaches are inherently less interactive and less interesting, as students primarily rely on textbooks and teachers' instructions [7]. However, using relevant technologies to support online learning poses several challenges to teaching practitioners [8]. Recognizing such a predicament, which has become more acute in this challenging time, more and more teachers are now resorting to new technologies to teach. Against such a backdrop, this study was conducted to determine the impact of an interactive mobile Augmented Reality (AR) application on a group of preschool children [9].

One of the essential skills that every pupil learns from the beginning of school is reading to make meaning from text and learn through reading with materials. Furthermore, good readers are phonemically aware, understand the alphabetic principle, apply these skills rapidly [10]. They are also required to be fluent, possess strong vocabulary and syntactic and grammatical skills, and relate reading to their own experiences [11]. Difficulties in any of these areas can impede reading development. Moreover, learning to read begins far before children enter formal schooling. Children who have stimulating literacy experiences from birth onward have an edge in vocabulary development, understanding reading goals, and developing an awareness of print and literacy concepts. By contrast, children who lack such rich experiences are most at risk of reading failure entering kindergarten and preschool [12].

One of the first steps a child will take on their reading journey is learning to recognize letters. Before a young learner can start to sound out words, blend syllables, or master other early reading foundations, they will need letter recognition skills [13]. Thus, it is essential to expand a child's letter recognition skills or engage their interest more purposefully by giving them appropriate learning aids and materials. Arguably, letter recognition activities that are fun, simple, and engaging would effectively help young children learn to read consistently and efficaciously [14]. In this regard, alphabet knowledge is a necessary component of emergent literacy development that refers to children's knowledge of letterforms, names, and corresponding sounds [15]. As such, alphabet knowledge is one of the best predictors of children's later reading and spelling abilities [16].

Furthermore, children who know the names of the letters have three significant advantages. Firstly, young children who know letter names will learn the sounds of the letters much more quickly. By contrast, young children who have difficulties understanding the letter names often have tremendous difficulty learning the sounds of the letters. Secondly, children who can easily name the alphabet letters have an easier time learning to read [15], [16]. Thirdly, as they know the letter names, children tend to be more motivated to discover more about the letters and the words around them [17].

This research aims to enhance preschool students' learning, and reading skills using a mobile AR application addressed as ABC Reading Kit. In addition, the findings of this study will have some assumptions for the educational practice of the science of 
learning and development, which teaching practitioners need to know when they teach children to learn to read. Specifically, this study aims to address the followings research objectives:

- To develop a mobile AR application that can help preschool students learn the alphabet more effectively.

- To improve preschool students' reading skills with the use of the proposed mobile AR reading kit.

- To improve preschool students' learning motivation with the use of the proposed mobile AR reading kit.

- To improve preschool students' self-learning with the use of the proposed mobile AR reading kit.

The following are the research questions of this study:

- Is there a significant difference in students' reading skills before and after using the mobile AR reading kit?

- Is there a significant difference in students' learning motivation before and after using the mobile AR reading kit?

- Is there a significant difference in students' self-learning before and after using the mobile AR reading kit?

Furthermore, this paper will characterize the subsection literature review for the research background and demonstrating the case studies related to the mobile application peculiarly on Augmented Reality and preschool learning environment. Besides, this paper also addressed the research design and highlighted the learning intervention for mobile learning. Subsequently, the research result will be reviewed related to the research objective and questions. Finally, this paper also delineates the conclusion and future works.

\subsection{Literature review}

As acknowledged, reading and writing skills are essential skills that preschool children should acquire to equip them for schooling at higher levels [18]. Therefore, mastering these skills is necessary to assist children to learn other school subjects more efficaciously in this challenging digital age [19]-[21]. Over the recent years, many studies have been carried out to examine a myriad of problems or issues regarding reading skills among preschool children aged five to six years [22]. Ideally, students need to possess good reading skills by demonstrating their ability to comprehend the texts they are reading [23], [24]. However, many studies have shown that most preschool children have been grappling with recognizing relevant alphabets, making it difficult for them to read smoothly [25], [26]. Preferably, teachers need to provide sufficient opportunities for students to revisit and revise the reading sections that students have already read. Revealingly, a study carried on by Hanley [27] depicted that more than $85 \%$ of preschool teachers lamented that many of their students could not recognize alphabets in the early stage of a reading lesson. Indeed, such a finding will cause some 
concerns among scholars and researchers. It will seriously impact student learning over the long term.

Revealingly, such teachers asserted that teaching young children entailed new, novel materials to make teaching and learning not only practical but also enjoyable [27]. They also emphasized the urgency of having interactive learning materials that could help attract students' attention and interest [28], [29]. Furthermore, recent studies have shown that preschool teachers need to rely on appropriate visual, audio, and kinesthetic elements to enhance teaching, rather than having students listen to verbal explanations or watch demonstrations passively [30]-[32].

Thus, teachers should expend novel reading kits to help students learn how to read with better efficacy and a high sense of enjoyment, which ultimately helps improve their students' reading skills and motivation based on the mobile application learning platform [2]. Ideally, the development of such reading kits should involve teachers who would provide the essential inputs or feedback to ensure such an application would be highly educational and appealing to help students learn to read effectively and enjoyably [33]. In this study, the development of the novel learning or reading kit was based on the marker-based augmented reality (AR) technology, which could run on desktop computers and mobile devices, notably smartphones. Utilizing this proposed reading kit, students would learn to read with a high degree of efficacy and motivation.
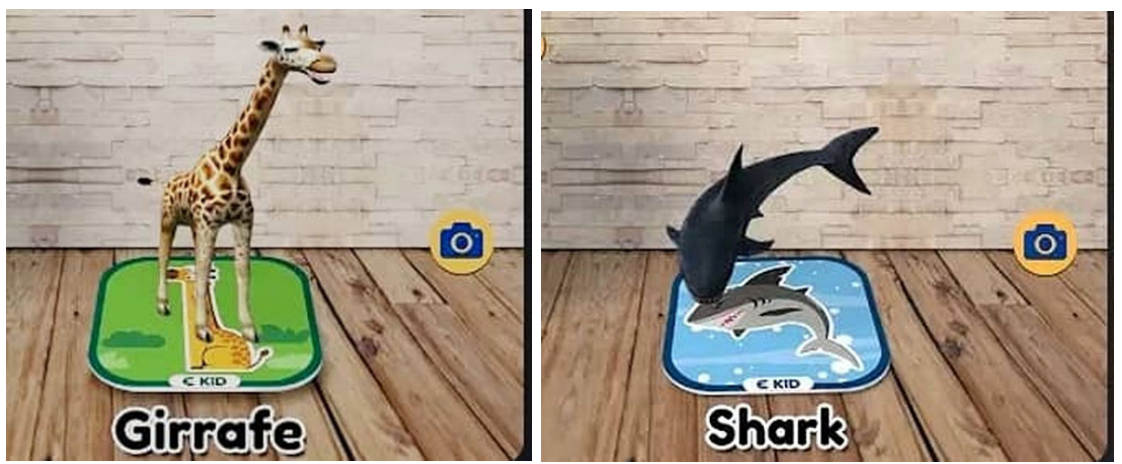

Fig. 1. Three-dimensional animal characters of the AR reading kit

A preliminary study involving 45 preschool teachers and 60 students (25 boys and 35 girls) from three preschools before the movement restrictions due to the pandemic. This study revealed several important aspects that need to be considered in developing the proposed reading kit to help improve preschool students' reading skills. Figure 1 shows some examples of the 3D animal characters utilized in the mobile AR reading kit.

Given the strong emphasis on this learning of late, this research attempts to evaluate the effectiveness of a mobile learning application that could facilitate self-learning to help preschool children recognize alphabets and read simple words. Teachers and students' parents could download the reading kit from the internet and installed it on their mobile devices, such as tablets and smartphones, as depicted in Figure 1. Practicing this application, students could learn at their own pace and place, effectively engaging in 
self-learning such as mobile applications, the use of which has become more pervasive due to the movement restrictions imposed by the Covid-19 pandemic [34]. Essentially, effective self-learning relies on a student's beliefs and expectations regarding accomplishing the intended learning goals. As such, it represents a unique feature of learning that empowers students to construct knowledge independently. Thus, the effectiveness of this type of learning requires children to have a strong willingness and motivation to ensure they could learn with greater ease and better ascendancy [35], [36]. With the proper instructional design, such a learning tool would assist preschool students to focus on learning activities. This contention is not untenable, as emerging evidence from recent studies has shown that self-regulated learning could nurture strong motivation and deep interest among young children to learn [37], [38].

Admittedly, the full impact of AR technology on student learning has been traversed involving a diversity of students' backdrops. However, not many studies have been devoted to studying the effects of such a novel technology on preschoolers' learning performances. Notwithstanding, the findings of a survey by Kritzenberger, who used a mixed reality platform to support cooperative learning, have shed some light on the understanding of the educational potentials of mobile AR applications for preschool and kindergarten education among young children [39]. Later, several studies emerged, such as Chen [40], [41], who developed and used a mobile AR learning tool to help young Chinese students learn the Chinese language's pronunciation and memorization.

Likewise, similar studies of mobile AR technology in various educational contexts have been conducted to assist student learning in diverse disciplines. For example, Hsieh and Lee's [42] and Hsieh and Lin's [43] studies were primarily concerned with examining the impacts of AR educational games on students' learning performances in English as a foreign language. Interestingly, their studies developed and used mobile AR learning applications consisting of virtual models and texts in dual languages, Chinese and English, to help students learn both languages interactively [44]. They observed that such interactions provided students with a sense of control and enjoyment that engendered engaging, meaningful learning [45]. Such applications have also been experimented with and explored in other study areas, such as mathematics, whereby serious educational games were utilized to adorn students' learning mathematics with enhanced efficacy [42].

\section{Research methods}

\subsection{Research design}

The sample of this study comprised several preschool students, whose ages ranged from four to six, who were selected from three preschools involving 60 students. An online survey using Google Form consisting of several questions aggregated data from the chosen preschool teachers. A conventional survey had to be ruled out given the outbreak of the Covid-19 pandemic that restricted any forms of physical contact. This study was based on the quantitative approach involving an experimental methodology based on a one-group pretest-posttest design. Essentially, such a design 
is comparable to the within-subjects experiment. Each participant will be tested first before treatment (pre-intervention) and then after treatment (post-intervention). In this study, the variables of interest to be measured were students' reading skills, motivation, and self-learning. The treatment involved a series of reading sessions spanning three weeks, each lasting for two hours.

In this study, Building Information Modelling (BIM) was applied to guide the design and development of the proposed mobile Augmented Reality (AR) reading kit. In principle, BIM is an established model that shows the development of the structure of a learning tool or application, the exchange of requisite information [46], [47], and better access to data [48]. By utilizing this model, two elements, namely the reading contents and AR elements, were considered essential to ensure the effectiveness of such a novel learning tool. Specifically, the AR elements comprised audio and visual elements, such as videos, to support interactive learning [49]. In recent years, self-directed learning has been widely used in many educational disciplines. The basis of this learning concept is the realization that students need to manage their learning activities online [50]. Several self-directed learning models, including Zimmerman's model [51], have been proposed to explain the different self-regulated learning processes. Invariably, the models emphasize the active participation of learners in online education, which undoubtedly hinges on students' interests and motivation [52]. Also, they emphasize the diverse learning styles of learners, which will have a significant impact on student learning in the self-directed learning mode.

The researchers also carried out a training program to train the teachers to utilize the mobile AR reading kit. Training materials, manuals, and booklets were prepared to guarantee that all the trainees would access relevant information to help them familiarize themselves with the novel learning tool [53]. Once they had demonstrated their ability to use the application, they were instructed to use it in their teaching activities. In the implementation phase, the preschool teachers utilized the reading kit containing animal characters to help preschool students to recognize alphabets and read words interactively, as depicted in Figure 2. The AR contents of the mobile reading kit were designed and developed based on the preschool literacy module, thus ensuring they were consistent with the objectives of the preschool curriculum. In the final phase, students' learning performance, motivation in reading, and self-learning were evaluated accordingly. Pre-testing and post-testing of these measures were carried out before and after the intervention, respectively. In addition, both descriptive and inferential statistical procedures were used to analyze the data. 


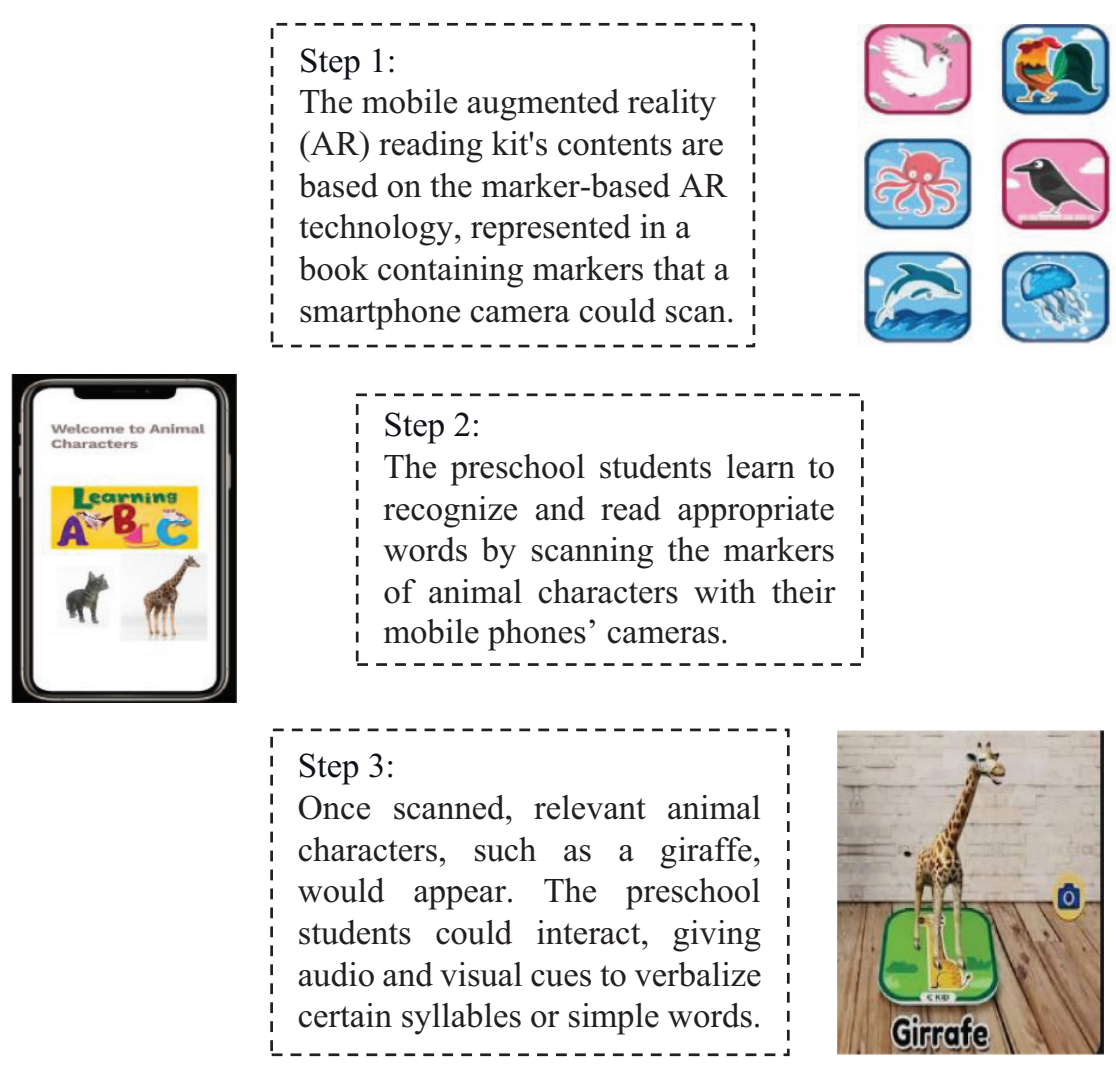

Fig. 2. The proposed development of the animal characters of the mobile augmented reality $(\mathrm{AR})$ reading kit

\section{Results and discussion}

The survey response rate was $98 \%$ after two of the returned forms of the questionnaire were found to be incomplete, which rendered them unusable for analysis. The data derived from the pre-and post-testing and survey were analyzed descriptively and inferentially utilizing Statistical Package for Social Sciences (SPSS) version 25.0. Specifically, one way-ANOVA was used to examine the research hypotheses of this study. Table 1 summarizes the results of the descriptive statistics of the data. 
Paper-Utilizing Animal Characters of a Mobile Augmented Reality (AR) Reading Kit to Improve..

Table 1. The descriptive statistics of students' reading skills, motivation, and self-learning

\begin{tabular}{|l|c|c|c|}
\hline \multicolumn{1}{|c|}{ Statistics } & Reading Skills & Motivation & Self-Learning \\
\hline Mean & 1.89 & 1.99 & 1.83 \\
\hline Std E.M* & 0.049 & 0.04 & 0.045 \\
\hline Median & 2 & 2.2 & 2 \\
\hline Mode & 1 & 1 & 1 \\
\hline Std. D & 0.855 & 0.889 & 0.996 \\
\hline Variance & 0.813 & 0.7662 & 0.989 \\
\hline
\end{tabular}

Note: Std. $\mathrm{EM}^{*}=$ Standard Error of Mean, Std. D = Standard Deviation

As shown in Table 1, the mean scores (standard deviations) of students reading skills, motivation, and self-learning were 1.89 (.855), $1.99(.889)$, and 1.83 (.996), respectively, indicating that the levels of such measures were moderate.

Table 2. ANOVA results of students' reading skills, motivation, and self-learning

\begin{tabular}{|l|c|c|l|c|c|c|c|c|}
\hline \multicolumn{1}{|c|}{ Dimension } & $\bar{x}$ & SD & $\begin{array}{c}\text { Source of } \\
\text { Variance }\end{array}$ & $\begin{array}{c}\text { Sum of } \\
\text { Squares }\end{array}$ & $\mathbf{d f}$ & $\begin{array}{c}\text { Mean } \\
\text { Square }\end{array}$ & F & $\mathbf{p}$ \\
\hline $\begin{array}{l}\text { Reading Skills } \\
\text { N=20 }\end{array}$ & 18.24 & 3.64 & Within Groups & 136.66 & 2 & 12.24 & 5.58 & 0.04 \\
\hline $\begin{array}{l}\text { Motivation } \\
\text { N=19 }\end{array}$ & 18.18 & 3.43 & Between Groups & 18.77 & 2 & 10.66 & 1.27 & 0.035 \\
\hline $\begin{array}{l}\text { Self-Learning } \\
\text { N=21 }\end{array}$ & 20.95 & 3.41 & Between Groups & 107.67 & 2 & 9.38 & 4.54 & 0.038 \\
\hline
\end{tabular}

Table 2 summarizes the results of the one-way-ANOVA analysis. As shown, there were significant differences in the students' reading skills $(F=5.58, p=.04)$, motivation $(\mathrm{F}=1.27, \mathrm{p}=.035)$, and self-learning $(\mathrm{F}=4.54, \mathrm{p}=.038)$ before and after the learning interventions. These findings showed that the students read more fluently and became more motivated to read independently through the self-learning mode using the mobile $\mathrm{AR}$ reading kit.

Based on these results, it could be argued that there was a notable and positive effect of the mobile augmented reality reading kit on students' reading skills after the intervention. In addition, their learning motivation had improved significantly, signifying the students had engaged in learning to recognize alphabets and read simple words quite independently. In other words, they were trained to learn to read with strong passion in the self-learning mode with minimal guidance from their teachers. Likewise, students were more engaged in self-learning after the intervention, indicating that the mobile learning application positively impacted students' engagement in such a learning mode [54]. Collectively, these findings are very encouraging. They suggest the animal characters of the mobile AR reading kit would attract preschool children's attention and interest in learning to recognize alphabets and read the words coherently [55].

Equally important, the findings are promising. Students' strong motivation would make them more receptive to using such a mobile application persistently, rather than using it once or twice. In addition, these steps should be emphasized that young children 
will regularly habituate such an application if they find it user-friendly, appealing, and enjoyable. Thus, it becomes imperative for mobile application developers to consider these factors when developing learning applications for young children [12]. Likewise, teachers should also demonstrate a strong passion and interest in using novel learning applications in their teaching practices. It is also important to acknowledge that the refusal of teaching practitioners to utilize digital learning objects is influenced by a host of factors, such as teaching workloads, a lack of training, and negative attitudes [56]. All these factors must be dealt with to assure the sustainability of such applications over a long period to ensure both teachers and students would reap their benefits.

\section{Conclusion}

Overall, the findings of this study demonstrated that the use of the mobile AR technology reading kit had significant impacts on students' learning performance in reading, learning motivation, and engagement in independent self-learning. These findings propose that such a technology could immerse students in an interactive, entertaining environment where they could explore and interact with digital learning objects, leading to better cognition. Furthermore, the learners would become highly motivated to learn with greater focus and experience meaningful self-learning in such an environment. Based on the results, the significant differences are apparent based on ANOVA analysis. Furthermore, the motivation and self-learning degree are increased based on the results portrayed within the groups, respectively.

Given these promising findings, preschool teachers could also embed such a novel tool into their teaching practices to enlighten the current movement restrictions due to the Covid-19 pandemic [57-58]. Such a tool is arguably indispensable. Furthermore, the students need to utilize a wide range of learning aids to help them engage in online learning. They could learn independently with minimal supervision.

\section{$5 \quad$ Future work}

The future work of this mobile for utilizing the animal characters is converging on improving the preschoolers' reading skills. The reading skills might be a significant focus on future development that could enhance reading skills. In addition, the material of stimulating the learners to be motivated is also exciting research to be unfolded afterward.

\section{Acknowledgment}

The authors wish to express their appreciation and gratitude to the Research Management Center of Sultan Idris Education University, Malaysia, for the Fundamental Education Research Grant (2020-0184-106-01) that helped support this research. 


\section{$7 \quad$ References}

[1] Ü. Gülten, "Does Student's Cognitive Flexibility Decrease During Pandemic? A New Approach to Measure Cognitive Flexibility," Int. J. Cogn. Res. Sci. Eng. Educ., vol. 9, no. 1, pp. 13-22, 2021. https://doi.org/10.23947/2334-8496-2021-9-1-13-22

[2] S. Papadakis, "Advances in Mobile Learning Educational Research (AMLER): Mobile learning as an educational reform," Adv. Mob. Learn. Educ. Res., vol. 1, no. 1, pp. 1-4, 2021. https://doi.org/10.25082/AMLER.2021.01.001

[3] A. P. Aguilera-Hermida, "College students' use and acceptance of emergency online learning due to COVID-19," Int. J. Educ. Res. Open, vol. 1, p. 100011, 2020. https://doi. org/10.1016/j.ijedro.2020.100011

[4] R. M. Strudwick, N. Cushen-Brewster, C. Doolan, and P. Driscoll-Evans, "An evaluation of the experiences of academics and practice educators who supported radiography students working on the temporary HCPC register during the COVID-19 pandemic," Radiography, 2021. https://doi.org/10.1016/j.radi.2021.07.001

[5] P. A. Rauschnabel, "Augmented reality is eating the real-world! The substitution of physical products by holograms," Int. J. Inf. Manage., vol. 57, p. 102279, 2021. https://doi. org/10.1016/j.ijinfomgt.2020.102279

[6] Y. Xu, J. C. Yau, and S. M. Reich, "Press, swipe and read: Do interactive features facilitate engagement and learning with e-Books?" J. Comput. Assist. Learn., vol. 37, no. 1, pp. 212-225, 2021. https://doi.org/10.1111/jcal.12480

[7] L. Demetri, C. A. Donnelley, M. C. MacKechnie, and P. Toogood, "Comparison of CaseBased Learning and Traditional Lectures in an Orthopedic Residency Anatomy Course," J. Surg. Educ., vol. 78, no. 2, pp. 679-685, 2021. https://doi.org/10.1016/j.jsurg.2020.08.026

[8] R. Scherer, S. K. Howard, J. Tondeur, and F. Siddiq, "Profiling teachers' readiness for online teaching and learning in higher education: Who's ready?," Comput. Human Behav., vol. 118, p. 106675, 2021. https://doi.org/10.1016/j.chb.2020.106675

[9] N. Alalwan, L. Cheng, H. Al-Samarraie, R. Yousef, A. I. Alzahrani, and S. M. Sarsam, "Challenges and prospects of virtual reality and augmented reality utilization among primary school teachers: A developing country perspective," Stud. Educ. Eval., vol. 66, p. 100876, 2020. https://doi.org/10.1016/j.stueduc.2020.100876

[10] J. Wang, J. Pines, M. Joanisse, and J. R. Booth, "Reciprocal relations between reading skill and the neural basis of phonological awareness in 7-to 9-year-old children," Neuroimage, vol. 236, p. 118083, 2021. https://doi.org/10.1016/j.neuroimage.2021.118083

[11] L. M. Henderson, E. van Rijn, E. James, S. Walker, V. C. P. Knowland, and M. G. Gaskell, "Timing storytime to maximize children's ability to retain new vocabulary," J. Exp. Child Psychol., vol. 210, p. 105207, 2021. https://doi.org/10.1016/j.jecp.2021.105207

[12] P. Dias and R. Brito, "Criteria for selecting apps: Debating the perceptions of young children, parents and industry stakeholders," Comput. Educ., vol. 165, p. 104134, 2021. https://doi. org/10.1016/j.compedu.2021.104134

[13] S.-M. Vehkavuori, M. Kämäräinen, and S. Stolt, "Early receptive and expressive lexicons and language and pre-literacy skills at 5; 0 years-A longitudinal study," Early Hum. Dev., vol. 156, p. 105345, 2021. https://doi.org/10.1016/j.earlhumdev.2021.105345

[14] S. K. Baker, R. T. Santiago, J. Masser, N. J. Nelson, and J. Turtura, "The Alphabetic Principle: From Phonological Awareness to Reading Words. Improving Literacy Brief.," Natl. Cent. Improv. Lit., 2018.

[15] S. B. Piasta and R. K. Wagner, "Developing early literacy skills: A meta-analysis of alphabet learning and instruction," Read. Res. Q., vol. 45, no. 1, pp. 8-38, 2010. https://doi. org/10.1598/RRQ.45.1.2 
[16] C. Schatschneider, J. M. Fletcher, D. J. Francis, C. D. Carlson, and B. R. Foorman, "Kindergarten prediction of reading skills: A longitudinal comparative analysis.," J. Educ. Psychol., vol. 96, no. 2, p. 265, 2004. https://doi.org/10.1037/0022-0663.96.2.265

[17] T. A. Roberts, P. F. Vadasy, and E. A. Sanders, "Preschoolers' alphabet learning: Letter name and sound instruction, cognitive processes, and English proficiency," Early Child. Res. Q., vol. 44, pp. 257-274, 2018. https://doi.org/10.1016/j.ecresq.2018.04.011

[18] D. K. Dickinson and M. V. Porche, "Relation between language experiences in preschool classrooms and children's kindergarten and fourth-grade language and reading abilities," ChildDev.,vol.82,no.3,pp.870-886,2011.https://doi.org/10.1111/j.1467-8624.2011.01576.x

[19] J. Viljaranta, N. Kiuru, M.-K. Lerkkanen, G. Silinskas, A.-M. Poikkeus, and J.-E. Nurmi, "Patterns of word reading skill, interest and self-concept of ability," Educ. Psychol., vol. 37, no. 6, pp. 712-732, 2017. https://doi.org/10.1080/01443410.2016.1165798

[20] K. Józsa and K. C. Barrett, "Affective and social mastery motivation in preschool as predictors of early school success: A longitudinal study," Early Child. Res. Q., vol. 45, pp. 81-92, 2018. https://doi.org/10.1016/j.ecresq.2018.05.007

[21] C. Vukelich, B. Enz, K. A. Roskos, and J. Kristie, "Helping young children learn language and literacy: Birth through kindergarten," 2019.

[22] A. Mahmood, B. Butler, H. Zen, and B. Jennings, "Key Early Verticals, Challenges and Limitations in Implementation of Augmented Reality." 2019. https://doi.org/ 10.1007/978-3-319-08234-9_273-1

[23] N. A. Abd Majid, H. Arshad, and F. Yunus, "Children and teacher's interaction for English pre-literacy using mobile augmented reality," Int. J. Educ., vol. 3, no. 15, pp. 71-78, 2018.

[24] U. C. Pendit, S. B. Zaibon, and J. A. A. Bakar, "Conceptual model of mobile augmented reality for cultural heritage site towards enjoyable informal learning aspect," J. Teknol., vol. 77, no. 29, 2015. https://doi.org/10.11113/jt.v77.6847

[25] M. Drouin, S. L. Horner, and T. A. Sondergeld, "Alphabet knowledge in preschool: A Rasch model analysis," Early Child. Res. Q., vol. 27, no. 3, pp. 543-554, 2012. https://doi. org/10.1016/j.ecresq.2011.12.008

[26] S. Papadakis, M. Kalogiannakis, and N. Zaranis, "Teaching mathematics with mobile devices and the Realistic Mathematical Education (RME) approach in kindergarten," Advances in Mobile Learning Educational Research, 1(1), 5-18, 2021. https://doi.org/10.25082/ AMLER.2021.01.002

[27] G. P. Hanley, T. A. Fahmie, and N. A. Heal, "Evaluation of the preschool life skills program in Head Start classrooms: A systematic replication," J. Appl. Behav. Anal., vol. 47, no. 2, pp. 443-448, 2014. https://doi.org/10.1002/jaba.132

[28] R. M. Yilmaz, "Augmented reality trends in education between 2016 and 2017 years," State art virtual Real. Augment. Real. Knowhow, vol. 81, p. 97, 2018. https://doi.org/10.5772/ intechopen.74943

[29] N. M. M. Barkhaya, N. D. A. Halim, and N. Yahaya, "The importance of augmented reality application for children's development during preschool years," Adv. Sci. Lett., vol. 24, no. 11, pp. 7935-7938, 2018. https://doi.org/10.1166/asl.2018.12460

[30] K.-H. Cheng and C.-C. Tsai, "Children and parents' reading of an augmented reality picture book: Analyses of behavioral patterns and cognitive attainment," Comput. Educ., vol. 72, pp. 302-312, 2014. https://doi.org/10.1016/j.compedu.2013.12.003

[31] Y. Kim and D. Smith, "Pedagogical and technological augmentation of mobile learning for young children interactive learning environments," Interact. Learn. Environ., vol. 25, no. 1, pp. 4-16, 2017. https://doi.org/10.1080/10494820.2015.1087411

[32] X. Wei, D. Guo, and D. Weng, "A study of preschool instructional design based on augmented reality games," in Chinese Conference on Image and Graphics Technologies, 2018, pp. 106-113. https://doi.org/10.1007/978-981-13-1702-6_11 
[33] M. Kursch, "Impact of a One-Off Demonstration on the Use of ICT in the Teaching of Andragogy Students on Their Change of Attitude Towards the Use of ICT in Education," Int. J. Cogn. Res. Sci. Eng. Educ., vol. 9, no. 1, pp. 121-134, 2021. https://doi. org/10.23947/2334-8496-2021-9-1-121-134

[34] S. Poultsakis, S. Papadakis, M. Kalogiannakis, and S. Psycharis, "The management of Digital Learning Objects of Natural Sciences and Digital Experiment Simulation Tools by teachers," Adv. Mob. Learn. Educ. Res., vol. 1, no. 2, pp. 58-71, 2021. https://doi. org/10.25082/AMLER.2021.02.002

[35] X. Wang, H. Sun, and L. Li, "An Innovative Preschool Education Method Based on Computer Multimedia Technology.," Int. J. Emerg. Technol. Learn., vol. 14, no. 14, 2019. https://doi.org/10.3991/ijet.v14i14.10714

[36] C. Moro, J. Smith, and E. Finch, "Improving stroke education with augmented reality: A randomized control trial,” Comput. Educ. Open, vol. 2, p. 100032, 2021. https://doi. org/10.1016/j.caeo.2021.100032

[37] A. Soltani and G. Askarizadeh, "How students' conceptions of learning science are related to their motivational beliefs and self-regulation," Learn. Motiv., vol. 73, p. 101707, 2021. https://doi.org/10.1016/j.lmot.2021.101707

[38] D. C. D. van Alten, C. Phielix, J. Janssen, and L. Kester, "Secondary students' online self-regulated learning during flipped learning: A latent profile analysis," Comput. Human Behav., vol. 118, p. 106676, 2021. https://doi.org/10.1016/j.chb.2020.106676

[39] T. Winkler, M. Herczeg, and H. Kritzenberger, Mixed reality environments as collaborative and constructive learning spaces for elementary school children. Association for the Advancement of Computing in Education (AACE), 2002.

[40] C.-H. Chen, C. C. Su, P.-Y. Lee, and F.-G. Wu, "Augmented interface for children Chinese learning," in Seventh IEEE International Conference on Advanced Learning Technologies (ICALT 2007), 2007, pp. 268-270. https://doi.org/10.1109/ICALT.2007.76

[41] P.-L. P. Rau, J. Zheng, and Z. Guo, "Immersive reading in virtual and augmented reality environment," Inf. Learn. Sci., 2021.

[42] H. S. Lee and J. W. Lee, "Mathematical education game based on augmented reality," in International Conference on Technologies for E-Learning and Digital Entertainment, 2008, pp. 442-450. https://doi.org/10.1007/978-3-540-69736-7 48

[43] M.-C. Hsieh and J.-S. Lee, "AR marker capacity increasing for kindergarten English learning," 2008.

[44] J. Buchner, K. Buntins, and M. Kerres, "A Systematic Map of Research Characteristics in Studies on Augmented Reality and Cognitive Load," Comput. Educ. Open, p. 100036, 2021. https://doi.org/10.1016/j.caeo.2021.100036

[45] C. S. C. Dalim, M. S. Sunar, A. Dey, and M. Billinghurst, "Using augmented reality with speech input for non-native children's language learning," Int. J. Hum. Comput. Stud., vol. 134, pp. 44-64, 2020. https://doi.org/10.1016/j.ijhcs.2019.10.002

[46] C. Blut, T. Blut, and J. Blankenbach, "CityGML goes mobile: application of large 3D CityGML models on smartphones,” Int. J. Digit. Earth, vol. 12, no. 1, pp. 25-42, 2019. https://doi.org/10.1080/17538947.2017.1404150

[47] J. Birt and N. Vasilevski, "Piloting Mobile Mixed Reality to Enhance Building Information Modelling Delivery in Construction Education," Res. Repos., p. 365, 2019.

[48] S. Tang, D. R. Shelden, C. M. Eastman, P. Pishdad-Bozorgi, and X. Gao, "A review of building information modeling (BIM) and the internet of things (IoT) devices integration: Present status and future trends," Autom. Constr., vol. 101, pp. 127-139, 2019. https://doi. org/10.1016/j.autcon.2019.01.020 
[49] J. B. Barhorst, G. McLean, E. Shah, and R. Mack, "Blending the real world and the virtual world: Exploring the role of flow in augmented reality experiences," J. Bus. Res., vol. 122, pp. 423-436, 2021. https://doi.org/10.1016/j.jbusres.2020.08.041

[50] S. Küçük, S. Kapakin, and Y. Göktaş, "Learning anatomy via mobile augmented reality: Effects on achievement and cognitive load," Anat. Sci. Educ., vol. 9, no. 5, pp. 411-421, 2016. https://doi.org/10.1002/ase.1603

[51] B. J. Zimmerman, "Attaining self-regulation: A social cognitive perspective," in Handbook of self-regulation, Elsevier, 2000, pp. 13-39. https://doi.org/10.1016/B978-012109890-2/ 50031-7

[52] M.-D. Dascalu et al., "Before and during COVID-19: A Cohesion Network Analysis of students' online participation in Moodle courses," Comput. Human Behav., vol. 121, p. 106780, 2021. https://doi.org/10.1016/j.chb.2021.106780

[53] P. N. Yu, "Consideration of the Basic Competencies of a Preschool Teacher in Curriculum Modernization,” Int. J. Cogn. Res. Sci. Eng. Educ., vol. 9, no. 1, pp. 91-103, 2021. https:// doi.org/10.23947/2334-8496-2021-9-1-91-103

[54] K. Bachnik, "Student evaluation of online learning during the COVID-19 pandemic," Technol. Forecast. Soc. Change, p. 121203, 2021. https://doi.org/10.1016/j.techfore. 2021.121203

[55] I. Arts, A. Fischer, D. Duckett, and R. van der Wal, "Information technology and the optimisation of experience-The role of mobile devices and social media in human-nature interactions," Geoforum, vol. 122, pp. 55-62, 2021. https://doi.org/10.1016/j.geoforum.2021.03.009

[56] K. Nikolopoulou, V. Gialamas, and K. Lavidas, "Habit, hedonic motivation, performance expectancy, and technological pedagogical knowledge affect teachers' intention to use mobile internet," Comput. Educ. Open, vol. 2, p. 100041, 2021. https://doi.org/10.1016/j. caeo.2021.100041

[57] T. Karakose, R. Yirci, and S. Papadakis, "Exploring the Interrelationship between COVID-19 Phobia, Work-Family Conflict, Family-Work Conflict, and Life Satisfaction among School Administrators for Advancing Sustainable Management," Sustainability, vol. 13, no. 15, p. 8654, 2021. https://doi.org/10.3390/su13158654

[58] T. Karakose, R. Yirci, S. Papadakis, T. Y. Ozdemir, M. Demirkol, and H. Polat, "Science Mapping of the Global Knowledge Base on Management, Leadership, and Administration Related to COVID-19 for Promoting the Sustainability of Scientific Research," Sustainability, vol. 13, p. 9631, 2021. https://doi.org/10.3390/su13179631

\section{Authors}

Hafizul Fahri Hanafi is a senior lecturer at the Faculty of Art, Computing and Creative Industry, Sultan Idris Education University (UPSI). He earned his Ph.D. from UPSI, specializing in Multimedia in Education. He has written many articles that have been published in Scopus and ISI journals. He is also an editorial board member of several local and international journals. Email: hafizul@,fskik.upsi.edu.my.

Kung-Teck Wong is an Associate Professor at the Faculty of Human Development, Sultan Idris Education University (UPSI), and is currently the Deputy Dean of Human Development (Research \& Innovation). He completed his Ph.D. at the University Malaysia Sabah and Post-Doctoral study at the University of South Australia, Australia (UniSA). To date, he has authored many articles that have been published in several leading local and international journals. 
Muhamad Hariz Muhamad Adnan is a senior lecturer in the Computing Department, Faculty of Arts, Computing and Creative Industry. He is also a data scientist at the National Child Development Research Centre (NCDRC). He has also written numerous Scopus- and ISI-indexed journals and proceedings.

Abu Zarrin Selamat is a senior lecturer at the Faculty of Human Sciences, Department of Moral, Civics and Character-Building Studies, Sultan Idris Education University. He is also a member of the editorial boards of the IjTVET, Dinamika Ilmu, and JoSSTed journals.

Nur Azlan Zainuddin is a lecturer in the Faculty of Art, Computing, and Creative Industry. He is also active in publishing numerous Scopus and ISI journals and proceedings in Multimedia.

Mohd Faizal Nizam Lee Abdullah is currently working at Universiti Pendidikan Sultan Idris (UPSI) as an Associate Professor in the Faculty of Science and Mathematics. He joined UPSI in 2005, and he has more than 15 years of teaching experience in mathematics education. Besides teaching, he is actively involved in doing research and publishing articles related to mathematics education.

Article submitted 2021-09-01. Resubmitted 2021-10-09. Final acceptance 2021-10-09. Final version published as submitted by the authors. 